\title{
Gas Sensing Characteristics of Phosphorus-decorated Molybdenum Disulfide Thin Films
}

\author{
Tae Hoon Kim ${ }^{1}$, Yeon Hoo Kim ${ }^{1}$, Ki Chang Kwon ${ }^{1}$, Seo Yun Park ${ }^{1}$, Ho Won Jang ${ }^{1 *}$ \\ ${ }^{1}$ Department of Materials Science and Engineering, Seoul National University, Seoul 151-744, \\ Republic of Korea \\ hwjang@snu.ac.kr
}

\begin{abstract}
In this work, we synthesized phosphorus-decorated $\mathrm{MoS}_{2}$ thin films as material for gas sensor through a solution process and chemical vapor deposition. Phosphorus-decorated $\mathrm{MoS}_{2}$ showed the higher gas sensing performance than the bare $\mathrm{MoS}_{2}$ thin films. With this method, higher sensitivity and selectivity can be achieved, resulting in the broad application of $\mathrm{MoS}_{2}$-based gas sensors.
\end{abstract}

Key words: Gas sensors, 2D TMDs, $\mathrm{MoS}_{2}$ thin film, phosphorus, Internet of Things

\section{Introduction}

In recent days, internet of things (loT) has increased enormous attentions and one of the most arising research areas on loT is the gas sensor. The gas sensors play an essential role in various fields. To meet loT requirements, the ease of integration of electronic circuits with low cost, small size and high sensing performances are crucial for gas sensors [1]. Among various types of gas sensors, chemoresistive gas sensors based on semiconductors have been considered as most applicable candidates for the loT because of their low cost and small size [2].

Two-dimensional (2D) materials are noteworthy because their characteristics, such as high surface-to-volume ratios and easy device fabrication are suitable to be applied as the active material of the gas sensors [3]. Since many transition metal disulfides, such as $\mathrm{MoS}_{2}$, $\mathrm{WS}_{2}$ and $\mathrm{SnS}_{2}$, are semiconducting with tunable bandgap energies depending on the thickness, the transition metal disulfides are inherently more desirable than graphene, metallic with zero band gap energy, for chemoresistive gas sensing applications [4]. In particular, $\mathrm{MoS}_{2}$ exhibited impressive gas sensing performances due to its high surface-to volume ratio, semiconducting properties, and plentiful active edge sites [5]. However, despite the increased interest and the diverse studies, the study of the relationship between the gas detection mechanism and the edge sites of $2 \mathrm{D}$ $\mathrm{MoS}_{2}$ have not been clarified.
Therefore, in order to discover the specific sensing mechanism, we synthesized phosphorus-decorated $\mathrm{MoS}_{2}$ by the chemical vapor deposition (CVD) method and solution process. Since the $\mathrm{MoS}_{2}$ is the $2 \mathrm{D}$ material, the decoration effect is expected to be higher than 3D materials. Therefore, decorating the $\mathrm{MoS}_{2}$ thin films with various materials can lead to unpredicted unique results.

\section{Method}

Pt interdigitated electrodes (IDE) were prepared and used as substrates for the sensor applications. The phosphorus-decorated $\mathrm{MoS}_{2}$ thin films were synthesized on the $1 \mathrm{~mm} \times 1$ $\mathrm{mm}$ size active area on the Pt IDE. The solution process and the CVD process were used to synthesize the P-decorated $\mathrm{MoS}_{2}$ thin films.

The sensing performances of the gas sensor based on the P-decorated $\mathrm{MoS}_{2}$ thin films were measured in a gas measuring device with a quartz tube and a furnace. The variations of the resistance were measured while the flowing gases were changing from dry air to the target gases with a source measurement unit. The mass flow controllers controlled the exact amount of gas flow, maintaining the constant flow rate of $1000 \mathrm{sccm}$.

\section{Results and Discussion}

Fig. 1 shows the response curves to $50 \mathrm{ppm}$ $\mathrm{C}_{2} \mathrm{H}_{5} \mathrm{OH}$ at $250{ }^{\circ} \mathrm{C}$ for $\mathrm{MoS}_{2}$ and phosphorusdecorated $\mathrm{MoS}_{2}$. Compared with the gas sensor based on the bare $\mathrm{MoS}_{2}$ thin films, the gas sensor based on the $\mathrm{P}$-decorated $\mathrm{MoS}_{2}$ thin 
films showed 50 times higher response for $\mathrm{C}_{2} \mathrm{H}_{5} \mathrm{OH}$ detection.

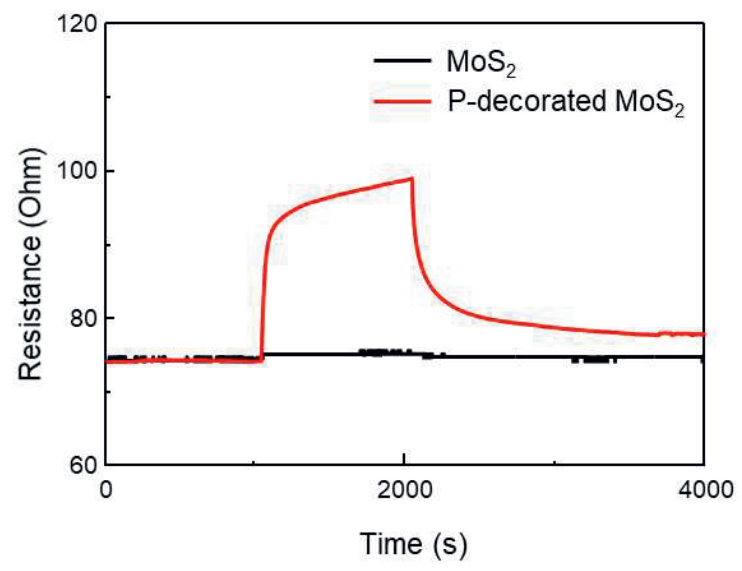

Fig. 1. Response curves of bare $\mathrm{MoS}_{2}$ and phosphorus-decorated $\mathrm{MoS}_{2}$ thin films to $50 \mathrm{ppm}$ $\mathrm{C}_{2} \mathrm{H}_{5} \mathrm{OH}$ at $250^{\circ} \mathrm{C}$..

Fig. 2 shows the responses of the $\mathrm{P}$-decorated $\mathrm{MoS}_{2}$ thin films to $50 \mathrm{ppm} \mathrm{C}_{2} \mathrm{H}_{5} \mathrm{OH}, \mathrm{CH}_{3} \mathrm{CHO}$, $\mathrm{C}_{6} \mathrm{H}_{6}, \mathrm{H}_{2}, \mathrm{CH}_{3} \mathrm{COCH}_{3}$, and 5 ppm NO $\mathrm{N}_{2}$ at 250 ${ }^{\circ} \mathrm{C}$.

The response of the sensor was calculated by eq. (1),

$\left(R_{\text {gas }}-R_{\text {air }}\right) / R_{\text {air }}=\triangle R / R_{a}$

Where, $R_{\text {air }}$ is the base resistance of the gas sensor in air condition and $\mathrm{R}_{\text {gas }}$ is the resistance when the target gas was fully adsorbed. The sensor showed the second highest response to $\mathrm{CH}_{3} \mathrm{CHO}$ and the response to $\mathrm{C}_{2} \mathrm{H}_{5} \mathrm{OH}$ was three times higher than the response to $\mathrm{CH}_{3} \mathrm{CHO}$. These results indicate that the $\mathrm{P}$ decorated $\mathrm{MoS}_{2}$ thin film is beneficial for the selective $\mathrm{C}_{2} \mathrm{H}_{5} \mathrm{OH}$ detection.

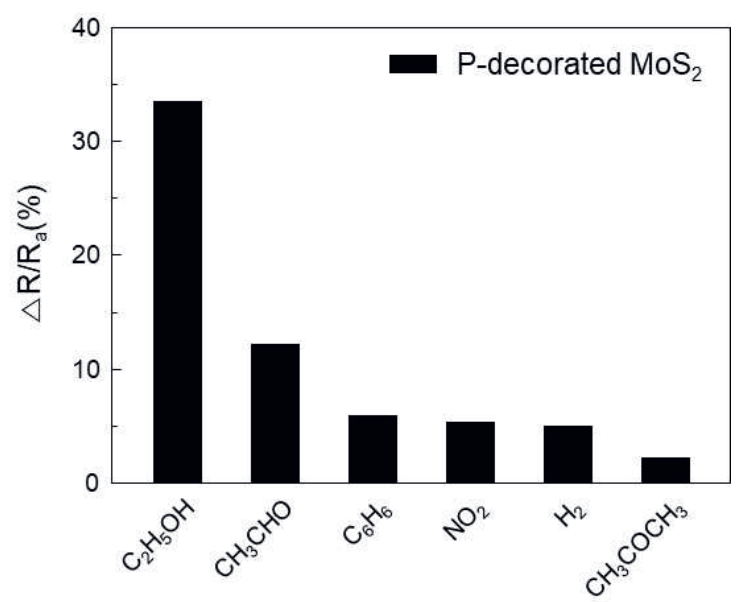

Fig. 2. Gas responses of phosphorus-decorated $\mathrm{MoS}_{2}$ thin films to $50 \mathrm{ppm} \mathrm{C}_{2} \mathrm{H}_{5} \mathrm{OH}, \mathrm{CH}_{3} \mathrm{CHO}, \mathrm{C}_{6} \mathrm{H}_{6}$, $\mathrm{H}_{2}, \mathrm{CH}_{3} \mathrm{COCH}_{3}$, and $5 \mathrm{ppm} \mathrm{NO} \mathrm{Na}_{2}$ at $250^{\circ} \mathrm{C}$.

\section{Conclusion}

We have investigated gas sensors based on phosphorus-decorated $\mathrm{MoS}_{2}$ thin films. The dangling bonds and base resistances were changed by the phosphorus atoms, resulting in the variation of the sensing performances. The sensor has the highest response to $\mathrm{C}_{2} \mathrm{H}_{5} \mathrm{OH}$ and the selective characteristic at $250{ }^{\circ} \mathrm{C}$. Since the $\mathrm{MoS}_{2}$ is the 2D material, more unprecedented sensing properties can be studied with the additional noble metal decoration which can broaden the potential of $\mathrm{MoS}_{2}$-based gas sensors.

\section{References}

[1] Y. H. Kim, S. J. Kim, Y. J. Kim, Y. S. Shim, B. H. Hong, H. W. Jang, ACS Nano 9, 10453-10460 (2015); doi: 10.1021/acsnano.5b04680.

[2] N. Yamazoe, K. Shimanoe, Sensors and Actuators B: Chemical 138, 100-107 (2009); doi: 10.1016/j.snb.2009.01.023.

[3] J. D. Fowler, M. J. Allen, V. C. Tung, Y. Yang, R B. Kaner, B. H. Weiller, ACS Nano 3, 301-306 (2009); doi: 10.1021/nn800593m.

[4] M. Chhowalla, H. S. Shin, G. Eda, L. Li, K. P. Loh, H. Zhang, Nature Chemistry 5, 263-275 (2013); doi: 10.1038/nchem.1589

[5] B. Cho, M. G. Hahm, M. Choi, J. Yoon, A. R. Kim, Y.-J. Lee, S.-G. Park, J.-D. Kwon, C. S. Kim and M. Song, Scientific Reports 5, 8052 (2015); doi: 10.1038/srep08052. 